\title{
Assessment for Catheter Function, Dressing Adherence and Device Necessity
}

\author{
Val Weston
}

\begin{abstract}
Vascular access devices (VADs) such as peripheral intravenous vascular catheters (PIVCs), peripherally inserted central catheters (PICCs) and central venous catheters (CVCs) are essential and common components of modern healthcare practice. In the USA, over 1.4 billion vascular access device procedures are undertaken annually, whilst in the UK, one in three patients will have at least one cannula inserted during their hospital stay. Such devices deliver a myriad of treatments ranging from fluid replacement and delivery of medications to laboratory blood sampling. However, these devices are not without their unwanted complications including phlebitis, thrombosis, dislodgement and bloodstream infections, some of which have the potential to be life threatening. Great emphasis has been placed on the insertion of these devices in reducing their potential risks. However, the right maintenance and care of these devices is equally important and is the focus of this chapter.
\end{abstract}

\section{Keywords}

Site assessment - Catheter function - Catheter care and maintenance $\cdot$ Dressing change

V. Weston $(\bowtie)$

Alder Hey Children's NHS Foundation Trust,

Liverpool, UK

e-mail: Valya.weston@alderhey.nhs.uk
Dressing adherence $\cdot$ Visual inspection - Site palpation - ANTT - Assessment for necessity

\subsection{Introduction}

Management of vascular access devices represents the largest portion of time in the Vessel Health and Preservation (VHP) cycle. Right management includes assessment of the insertion site, dressing and device function prior to each infusion. Care and management using right infection prevention methods including Aseptic Non Touch Technique (ANTT) for device handling, disinfection of access site, pulsatile flushing the device before and after infusions, performing dressing changes consistent with policies and evaluation of device necessity with prompt removal when the VAD is no longer needed are cornerstones to safe patient care. Incorporated into management are the right supplies and technology needed to ensure the right outcomes. Right management is a process that requires consistency established through commitment to education, policy development based on guidelines and research and consistent evaluation of outcomes.

Care and maintenance of peripheral or central venous devices represents the longest period of time in the life of a VAD. Complications are more prevalent during this period and require close assessment with device removal as soon as no 
longer needed. Management of VADs requires assessment of function, dressing integrity and evaluation of the insertion site integrated with consistent disinfection prior to infusion access, flushing and evaluation for device necessity. Each of these components represents a level of safety necessary to protect the patient receiving intravenous treatments.

\subsection{Assessment}

Assessment is the active process of inspecting, monitoring and evaluating a vascular access device (VAD) and includes assessing the entire infusion system, from the solution container to the VAD insertion site (Gorski et al. 2016). The objective of these assessments is to monitor the device for complications, patency, position, function and necessity. The aim is to prevent the interruption of treatment, to assess the patency of the device and to detect signs of infection or other complications at the earliest possible stage (Moureau 2013; Loveday et al. 2014; RCN 2016).

Moureau (2013) identifies the five main components of VAD assessment as cannulation site, dressing, tubing or giving set labelling, catheter function and device necessity. Additionally, the RCN (2016) recommends the documentation of the ongoing care and maintenance of the device to include:

1. Details of the catheter care (Loveday et al. 2014)

2. Site and device care-to include appearance using local assessment scales for phlebitis

3. Dressing changes

4. Methods to evaluate the functioning of the VAD prior to use (Bodenham et al. 2016)

5. Continued documentation of the external or exposed length of the CVC or PICC line to monitor migration

6. Flush solution used to include type, volume, frequency and difficulties encountered

The Vessel Health and Preservation tool and framework produced in the USA and in the UK advocates the inclusion of a section for the daily assessment and evaluation of the VAD to assess for complications to determine if the VAD remains the right choice and indeed whether it is still needed (Moureau et al. 2012; Hallam et al. 2016) (see Fig. 17.1).

\subsection{How Often Should the VAD Be Assessed?}

\subsubsection{Peripheral Intravenous Vascular Catheters (PIVCs)}

Gorski et al. (2016) recommend that PIVCs be assessed by staff at least once every $4 \mathrm{~h}, 1-2$ hourly for patients who are critically ill or sedated or who have cognitive impairment. These assessments need to increase to hourly for neonate and paediatric patients and more often when dealing with patients who are receiving an infusion of a vesicant medication or chemotherapeutic agent.

Alternatively, Loveday et al. (2014), NICE (2014) and the RCN (2016) recommend that the PIVC should be assessed every shift at a minimum. However, Ray-Barruel et al. (2014) in their systematic review reported that the frequency for phlebitis assessments to highlight the risk of infection ranged from every time the device was accessed for medication or infusions to twice daily, daily or even every other day. Therefore, there is clearly a difference of opinion in the frequency and timing of recommendations for assessments, and as recommended by RCN (2016), the frequency for assessment should be set out in organisational policies and procedures based on good-quality clinical evidence.

\subsubsection{CVC and PICCs}

NICE (2014), Gorski et al. (2016) and Hallam et al. (2016) recommend that CVC, PICC and midline catheters be assessed on a daily basis, whilst Loveday et al. (2014) recommend that CVC and PICC catheters should be assessed at least once a shift for signs of inflammation, infiltration or blockage. 
Daily assessment

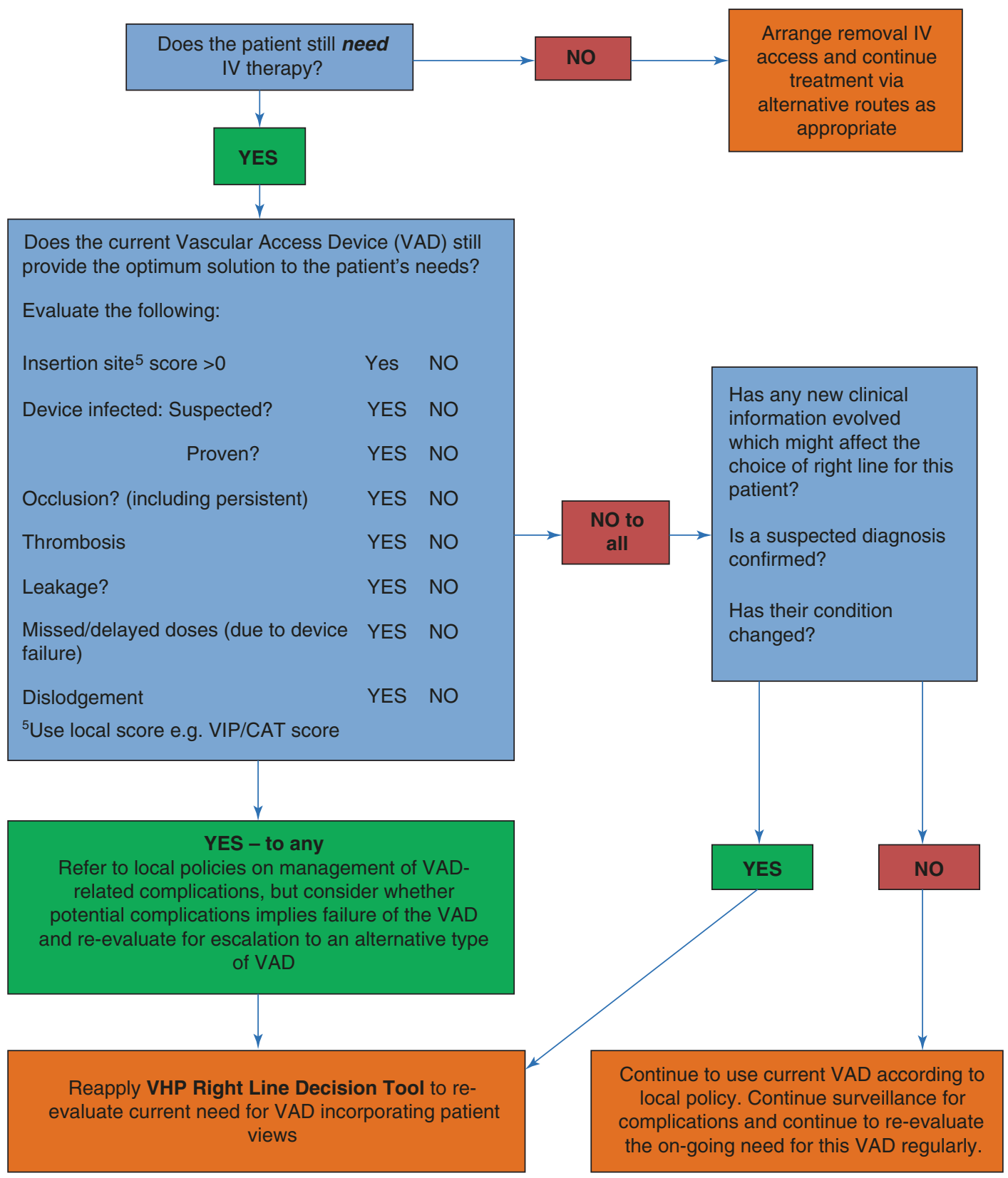

Fig. 17.1 Daily assessment chart (used with permission from Hallam et al. 2016)

\subsubsection{Outpatients and Home Care}

Tice et al. (2004) recommend that the VAD should be monitored daily, short and midlines twice weekly and CVCs at least once a week, whilst Chapman et al. (2012) and Gorski et al. (2016) advise that the patient and/or the care giver must have training to be able to check and assess the VAD at least once per day for signs of complications and report immediately any signs or symptoms of dressing dislodgement to their healthcare provider. Chapman et al. (2012) additionally recommend that the outpatient antibiotic 
therapy (OPAT) nurse specialists or other vascular nurse specialists must be satisfied of the patient/care giver competency in caring for and assessing the VAD and that this competency should be documented.

For paediatric care Chapman et al. (2012) recommend that the care giver or a family member must be capable of delivering/providing the necessary care for the patient.

\subsection{Inspection of the VAD Insertion Site}

The site inspection begins with a visual inspection of the VAD insertion site, assessing for redness, swelling or any signs of infection or other complications.

After the visual inspection, hands are decontaminated, and gloves are donned. The site is gently palpated through the dressing to determine if there are any signs of pain tenderness, firmness, blanching, moisture, oedema or oozing. All findings are noted and documented in the patient record (Moureau 2013). If possible, the patient is consulted to determine whether he or she is feeling pain or discomfort at the site or when medications are being administered. However, for patients with cognitive impairment and communication difficulties, this may not be possible; the practitioner will need to assess through body language if the patient is feeling discomfort or pain.

The catheter position is checked and measured to ensure it has not migrated in or out of the cannulation site. For central venous catheters (CVCs) and peripherally inserted central catheters (PICCs), this is verified by comparing the current external length of the catheter with the baseline measurement documented on the initial insertion of the cannula (Moureau 2013; Gorski et al. 2016). The upper arm circumference can be measured when clinically indicated to assess the presence of oedema and possible deep vein thrombosis (DVT). The measurement is taken $10 \mathrm{~cm}$ above the antecubital fossa and is compared to the baseline measurement to detect possible catheterassociated venous thrombosis. A $3 \mathrm{~cm}$ increase in arm circumference and the presence of oedema may be associated with an upper arm DVT.

\subsection{Dressings and Dressing Changes}

Next, the dressing is assessed. Remember, once the skin has been punctured for the insertion of the $\mathrm{VAD}$, the dressing provides the only protective barrier keeping microorganisms from entering the body through the insertion site. The practitioner ensures that the dressing is completely intact, that all edges are adhering to the skin and that the dressing is clean and dry. The dressing should be replaced if its integrity has been compromised by moisture, drainage or blood under the dressing, if there are signs of sheering or dislodgement of the dressing or if there are signs and symptoms of infection such as redness, exudates or pain (Gorski et al. 2016; RCN 2016).

Following placement of a VAD, a dressing is used to protect the insertion site. The two most common types of dressings used for insertion sites are sterile, transparent, semipermeable polyurethane dressings with a layer of an acrylic adhesive (transparent dressings) and gauze and tape (Loveday et al. 2014). Transparent film dressings are used to cover VAD insertion sites whenever possible (Loveday et al. 2014; RCN 2016) to minimise the risk of extra luminal catheter contamination (Rupp et al. 2013). Transparent dressings are permeable to water, vapour and oxygen and impermeable to microorganisms.

After insertion the practitioner should ensure that the dressing is completely intact, that all edges are adhering to the skin and that the dressing is clean and dry. The dressing should be replaced if its integrity has been compromised by moisture, drainage or blood under the dressing, there are signs of sheering or dislodgement of the dressing or if there are signs or symptoms of infection such as redness, exudate or pain (Gorski et al. 2016; RCN 2016).

A gauze dressing is used if there is drainage of blood or fluid from the catheter exit site or if the patient has profuse perspiration (Loveday et al. 2014; Gorski et al. 2016; RCN 2016).

Ensure dressings are secure to reduce the risk of loosening or dislodgement of the catheter, as frequent dressing changes are associated with an increased risk of infection (Gorski et al. 2016) 
Table 17.1 Current guidance available for the frequency of dressing changes

\begin{tabular}{|c|c|c|c|}
\hline Dressing changes & Epic3_Loveday et al. (2014) & $\begin{array}{l}\text { Infusion therapy standards } \\
\text { of practice-Gorski et al. } \\
(2016)\end{array}$ & $\begin{array}{l}\text { Standards for infusion therapy } \\
\text { (fourth edition)-RCN (2016) }\end{array}$ \\
\hline $\begin{array}{l}\text { Transparent } \\
\text { semipermeable } \\
\text { membrane dressing } \\
\text { (TSM, transparent } \\
\text { dressing) }\end{array}$ & $\begin{array}{l}\text { Every } 7 \text { days or sooner if } \\
\text { the integrity of the dressing } \\
\text { is compromised }\end{array}$ & $\begin{array}{l}\text { At least every } 5-7 \text { days } \\
\text { or more frequently if the } \\
\text { dressing becomes damp, } \\
\text { loosened or visibly } \\
\text { soiled }\end{array}$ & $\begin{array}{l}\text { Every } 7 \text { days or sooner if } \\
\text { the integrity of the dressing } \\
\text { is compromised }\end{array}$ \\
\hline $\begin{array}{l}\text { Gauze or gauze under a } \\
\text { transparent dressing }\end{array}$ & $\begin{array}{l}\text { Change when inspection of } \\
\text { the site is necessary or when } \\
\text { the dressing becomes damp } \\
\text { loosened or soiled } \\
\text { Change the gauze to a } \\
\text { transparent dressing as soon } \\
\text { as possible }\end{array}$ & Every 2 days & $\begin{array}{l}\text { Change when inspection of } \\
\text { the site is necessary or when } \\
\text { the dressing becomes damp } \\
\text { loosened or soiled } \\
\text { Change the gauze to a } \\
\text { transparent dressing as soon } \\
\text { as possible }\end{array}$ \\
\hline Post insertion dressing & Changed after $24 \mathrm{~h}$ & & Changed after $24 \mathrm{~h}$ \\
\hline
\end{tabular}

due to the risk of loosening or dislodging the catheter during dressing removal.

The practitioner should check to see if a dressing change is required according to standards and local protocols. A dressing is changed immediately, and the site is closely assessed, cleaned and disinfected if there is evidence of leakage, site tenderness and other signs of infection or if the dressing becomes loose or dislodged (see Table 17.1).

Compliance with recommended dressing change days is necessary to prevent endogenous patient flora/bacteria from infecting the catheter down the cannulation line.

It is recommended to use chlorhexidine gluconate-impregnated dressings over central VADs to reduce the risk of infection from an extra luminal source (Timsit et al. 2012; Loveday et al. 2014; Ullman et al. 2015; Gorski et al. 2016).

\subsection{Securement}

It is vitally important to secure VAD particularly PIVC, non-tunnelled central lines and PICC lines. Failure to adequately secure the VAD increases the risk of infection, malposition, treatment delays/failure and extravasation and can lead to premature removal of the VAD (Gorski et al. 2016). Dressings alone should not be relied on to stabilise the VAD, and a stabilisation device should be used.

There are two main types of stabilisation devices: adhesive-based devices or subcutaneous engineered stabilisation device. The choice of securement device should be based on a risk assessment considering the patients age, skin integrity, previous adhesive skin injury and any type of drainage from the insertion site (Gorski et al. 2016). Securement devices are covered in more detail in Chap. 9.

Assess the integrity of the stabilisation device at each dressing change, and change the device according to the manufacturer's directions for use. Remove adhesive devices during dressing change to allow for appropriate skin antisepsis, and then apply a new device (Gorski et al. 2016). Usually, subcutaneous engineered stabilisation devices can stay in place for the duration of the device and can be lifted to achieve skin antisepsis at each dressing change.

\subsection{Tubing/Giving Set Labelling}

Infusion tubing/giving sets aid in the administration of medications and fluids and are connected to the VAD. Standards and subsequent local policies and procedures establish the correct length of time that the tubing/giving set can be used based on the types of solutions being administered through them.

During the assessment of the VAD, ensure that the tubing/giving set change dates are checked, including additional equipment used for the administration of intravenous medications and solutions (Moureau 2013; Gorski et al. 2016; RCN 2016). 


\subsection{Catheter Function}

Catheter function is addressed during each site assessment and with each use to check the flow and patency of the catheter.

Firstly, the practitioner checks to see if the catheter flushes easily without sluggishness as this is generally the first sign of a partial occlusion in the catheter. Ideally, flow should be easy and smooth without resistance. Once flow has been assessed, aspiration can be performed to check for a brisk blood return. The catheter should then be flushed again to clear the blood from the lumen. An inability to aspirate blood or flush the catheter may be resolved through flushing if identified early enough. (This is covered in more detail in the following chapters).

If sluggishness with blood flow or flushing is present in a CVAD, blood buildup may have formed within the walls of the catheter making it necessary to instil a thrombolytic solution to clear the catheter. Any problems regarding catheter function should be addressed and remedied promptly to avoid a delay in treatment, complete loss of function of the catheter and increased risk of infection (Moureau 2013).

\subsection{Complication Prevention During Site Assessment and Management}

\subsubsection{Infection}

All invasive devices are a known source of infection with VADs having a greater risk for bloodstream infections. Although evidence demonstrates that some cannulation sites such as the femoral vein carry a higher risk of infection (CDC 2011; RCN 2016), all devices have a risk regardless of where they are placed.

Sources of bacterial contamination and subsequent infection for any VAD include:

1. Practitioner hands-direct contact

2. Patient skin

3. Catheter hubs
4. Catheter tubing/giving sets

5. Infusates

6. Contamination of equipment-indirect contact

To prevent infection, specific steps must be taken to prevent the bacteria from entering the body through a portal of entry. It is the practitioner's duty to ensure the patient is kept safe by employing simple and timely management strategies to minimise the risk of infection. Examples of infection prevention strategies include the use of gloves during site assessment, disinfection of patient's skin during dressing changes and disinfection of the catheter hub prior to each access, all of which are discussed thoroughly in later chapters.

\subsubsection{Phlebitis}

Phlebitis, or inflammation of the vein, is one of the complications the clinician is looking for during a site assessment. Phlebitis has four main root causes and is classified and treated based on its origin. The four classifications of phlebitis are as follows:

- Chemical Phlebitis: associated with infusates administered to the patient or with skin antiseptics that have not fully dried and are pulled into the vein during device insertion

- Mechanical Phlebitis: associated with vein wall irritation caused by the catheter being too large for the vasculature, catheter movement, insertion trauma or catheter material and stiffness

- Bacterial Phlebitis: associated with bacterial contamination or colonisation of the VAD or the intravenous site

- Post-Infusion Phlebitis: may occur up to $48 \mathrm{~h}$ after removal of the device, necessitating continued assessment of the site

Phlebitis can cause a patient severe discomfort and interrupt therapy resulting in delayed treatment and, in the case of a PIVC, the need for the device to be resited. Repeated incidences of phlebitis may lead to difficulty with venous access 
and a possible need for more advanced venous access (Marsh et al. 2015). Phlebitis is treated based on its cause. See Table 17.2 for phlebitis interventions.

Table 17.2 Summary of phlebitis interventions recommended by Gorski et al. (2016)

\begin{tabular}{l|l}
\hline $\begin{array}{l}\text { Type of } \\
\text { phlebitis }\end{array}$ & Intervention \\
\hline Chemical & $\begin{array}{l}\text { Evaluate infusion therapy and need for } \\
\text { different vascular access, different } \\
\text { medication or slower rate of infusion. } \\
\text { Determine if catheter removal is needed }\end{array}$ \\
\hline Mechanical & $\begin{array}{l}\text { Stabilise catheter, apply heat, elevate } \\
\text { limb, provide analgesia, monitor for } \\
\text { 24-48 h, and if symptoms persist } \\
\text { consider removal of the catheter }\end{array}$ \\
\hline Bacterial & $\begin{array}{l}\text { If suspected, remove catheter. Discuss } \\
\text { with physician the need for further } \\
\text { vascular access }\end{array}$ \\
\hline $\begin{array}{l}\text { Post- } \\
\text { infusion }\end{array}$ & $\begin{array}{l}\text { If bacterial source, monitor for signs of } \\
\text { systemic infection } \\
\text { If nonbacterial, apply warm compress, } \\
\text { elevate limb, and provide analgesia }\end{array}$ \\
\hline
\end{tabular}

Phlebitis is diagnosed by observation of clinical signs or when a patient reports various symptoms. The insertion site should be visually assessed and documented during every shift at a minimum, and in the case of a PIVC, a visual infusion phlebitis score (Figs. 17.2, 17.3, and 17.4) (Jackson 1998) or other standardised phlebitis scale should be recorded (Loveday et al. 2014; Gorski et al. 2016; RCN 2016).

Gorski et al. (2016) recommend that phlebitis incidents causing harm or injury should be reviewed for quality improvement opportunities.

\subsection{Keeping the Patient Safe During Site Assessment and Catheter Maintenance}

Up to $99 \%$ of the catheter life happens after initial placement of a vascular access device. It is estimated that $71.7 \%$ of CVAD infection occur 5 days or more after insertion, during

\begin{tabular}{|c|}
\hline $\begin{array}{l}\text { Visual Infusion Phlebitis Score } \\
\text { IV site appears healthy }\end{array}$ \\
\hline $\begin{array}{l}\text { One of the following is evident: } \\
\text { - Slight pain at IV site - Redness near IV site }\end{array}$ \\
\hline $\begin{array}{l}\text { Two of the following are evident: } \\
\text { - Pain - Erythema - Swelling }\end{array}$ \\
\hline $\begin{array}{l}\text { All of the following signs are evident: } \\
\text { - Pain along the path of the cannula } \\
\text { - Erythema - Induration }\end{array}$ \\
\hline $\begin{array}{l}\text { All of the following signs evident and extensive: } \\
\text { - Pain along the path of the cannula } \\
\text { - Erythema - Induration } \\
\text { - Palpable venous cord }\end{array}$ \\
\hline $\begin{array}{l}\text { All of the following signs are evident and extensive } \\
\text { - Pain along the path of the cannula - Erythema } \\
\text { - Induration - Palpable venous cord - Pyrexia }\end{array}$ \\
\hline (c) Andrew Jackson 1997 Rotherham General Hospitals NHS Trust \\
\hline
\end{tabular}

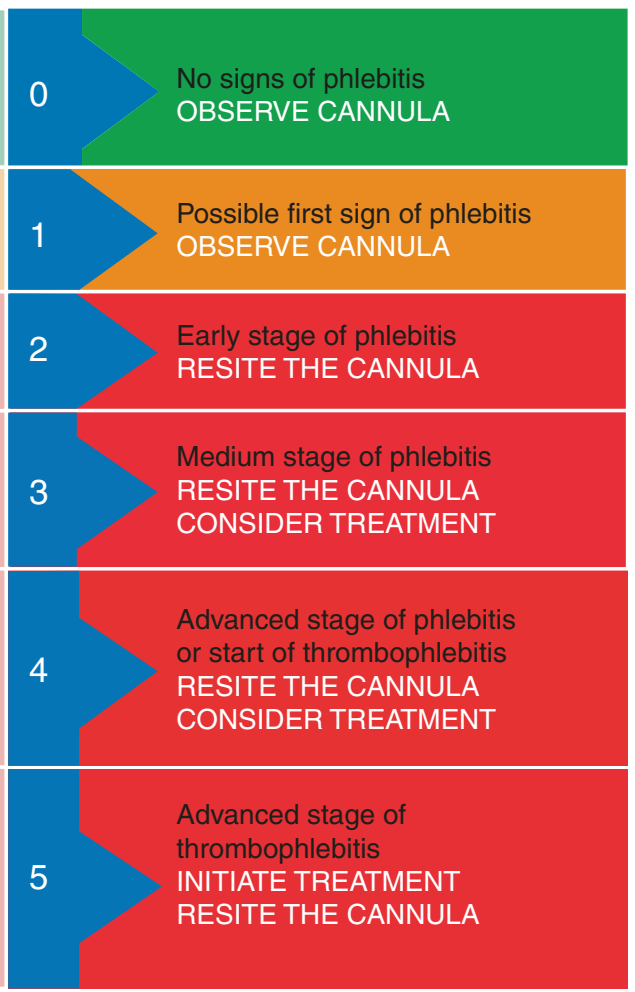

Fig. 17.2 Visual phlebitis score (used with permission from A. Jackson, www.IVTeam.com) 


\section{Daily Vessel Health Assessment Tool}

Patient Medical ID \#:

Date:

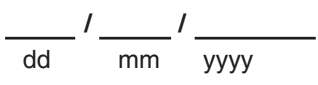

Nursing Information

1. How comfortable is the patient with their vascular access device? (ask the patient)
$\square 5$ - Extremely comfortable
$\square 4$ - Somewhat comfortable
$\square 2$ - Somewhat uncomfortable
ㅁ 3 - Comfortable
$\square 1$ - Very uncomfortable
$\square$ N/A due to confusion /sedation or other

If \#2 or \#1 checked, please explain the reason for discomfort:

2. What is the current device(s)? (check all that apply)

$\begin{array}{lllllll}\text { Type: } \quad \square \text { PIV } & \square \text { Midline } & \square \text { PICC } & \square \text { CVC } & \text { P Port } & \square \text { Dialysis } & \\ \text { Number of Lumens } & \square 1 & \square 2 & \square 3 & \text { Which Device? } & \square \text { PICC } & \square \text { CVC } \\ \text { No. of Lumens in Use } & \square 1 & \square 2 & \square 3 & \text { Which Device? } & \square \text { PICC } & \square C V C\end{array}$

3. What complications, if any occurred within the last 24 hours (PIV)? (check all that apply)
$\square$ Infiltration
$\square$ Multiple restarts in $24 \mathrm{hrs}$
$\square$ Phlebitis/thrombophlebitis
$\square$ Infection
口Other

4. Did any complications occur within the last 24 hours with Central Venous Access Device(s)? $\square$ Yes $\square$ No
If Yes, check all that apply. Which Device $\square$ PIV
$\square$ Infection
$\square$ Phlebitis
$\square$ Midline
$\square \mathrm{PICC}$

$\square$ Occlusion

$\square$ Partial Withdrawal Occlusion $\quad \square$ Thrombosis

$\square$ Other

5. Is this patient having any difficulty with eating and drinking?

6. Are there IV medications ordered other than PRN?

7. Is the VAD absolutely neccessary for blood draws with this patient?

$\begin{array}{ll}\square \text { Yes } & \square \text { No } \\ \square \text { Yes } & \square \text { No } \\ \square \text { Yes } & \square \text { No }\end{array}$

Nursing Recommendation:

Print Name: RN/NP/PA/IVRN (circle)

8. Referring to the VHP Right Line Tool is the Venous access device(s) most appropriate for the current treatment plan?

If No, What device would apply based on Right Line Tool Selection?

$\square$ Yes $\square$ No

9. Is there any reason to maintain the current device(s)?

If Yes, (other than the above reason) Why?

RECOMMENDATIONS:

$\square$ Discontinue device(s) $\square$ Maintain device(s)

$\square$ Consider new device(s) from VHP Assessment Trifold Recommended new device(s)

Physician/Pharmacist Info:

Print Name: $\mathrm{MD} /$ PharmD (circle)

(Information can be obtained by interview or by phone)

10. would switch to all oral medications be contraindicated at this time for this patient?

11. Is there an active blood stream infection?

12. Will access be required once the patient is released?

13. What is the current discharge plan?

14. Is the current IV device still necessary for this treatment plan and this patient? If Yes, please explain:

$\square$ IV needed additional days Number of additional day(s)

$\square$ Critical condition

Number

\section{Action Plan:}

See nursing recommendation(s). If two or more NO answers, consider discontinuation of all IV devices to reduce risk to patient.

FINAL ACTION:

$\square$ Discontinue device(s)

Maintain device(s)

For internal review:

\# day(s)

g. 17.3 Daily assessment (used with permission from the Teleflex)

maintenance of these devices (Davis 2011). Protocols have been established to promote patient safety during maintenance and manipulation of vascular access devices; these protocols include proper hand hygiene, the use of personal protective equipment, proper patient skin antisepsis during dressing changes and the use of aseptic technique throughout the maintenance and manipulation of all vascular access devices. It is the clinician's responsibility to adhere to the established protocols to ensure patient safety. 


\section{SAMPLE DAILY MONITORING TOOL}

Clinical assessment due between 7A and 7p shift each day for each patient

Patient Name and Room Number:

Date:

\section{Clinician Name:}

Please notify PICC/VAS Team if advanced assessment of device is needed.

\section{Daily Assessment for Site Necessity:}

Current Intravenous Devices (list all with quantity):

PIV \#1 Location: R / L; describe location size length of time in place (hrs/days)

\section{Describe usage:}

PIV \#2 Location: R / L; describe location size

length of time in place (hrs/days)

\section{Describe usage:}

PICC Location: R / L; describe location

size

lumens

Describe usage:

CVC Location (Chest/Neck): R / L; describe

location

lumens

Describe usage:

Port Location: R / L; describe location

Describe usage:

\section{Current Infusions:}

Fluid Infusion - Type

Pain Meds $\square$ Intravenous Medications Check all that apply:

Antibiotics

Blood Draws from CVC, frequency

\section{Venous Access Requirements:}

Peripheral sites adequate for prescribed therapy currently

Peripheral vein sites available (prescriptive medications include known vein irritants)

Consider: $\square$ Temporary Antimicrobial CVC $\quad \square$ PICC $\square$ Tunneled CVC $\square$ Port

Limited peripheral sites - Central Venous Catheter needed

Consider: $\square$ Temporary Antimicrobial CVC $\quad \square$ PICC $\square$ Tunneled CVC $\square$ Port

Refer to Advanced Inserter under Vein Sparing Protocol -assessment related to patient diagnosis, complications as an inpatient and infusion history

Fig. 17.4 Monitoring tool (used with permission from the Teleflex) 


\subsection{Extravasation and Infiltration}

Extravasation and infiltration are the result of fluids and medication inadvertently being infused into the surrounding tissues of the vessel in which the VAD is located (RCN 2016) and may occur in over a third of patients receiving IV therapy (Al-Benna et al. 2013). The term infiltration is used when a non-vesicant solution has been used and often doesn't cause long lasting damage compared to extravasation which is caused by vesicant solutions and can cause major tissue damage which may require plastic surgical interventions.

The risk of both extravasation and infiltration complications is more common in PIVC than central lines and can be prevented by choosing the appropriate IV gauge, care site selection, effective securement of the device and the frequent assessment of insertion site (Dwyer and Rutkowski 2016; Gorski et al. 2016).

The early detection and response to extravasation injuries can minimise the long-term damage. Extravasation of vesicant solutions is firstly noted by pain and swelling around the insertion site followed by blanching, blistering and discoloration of the skin, but it is usually pain that alerts the patient of the problem (Al-Benna et al. 2013).

Each medical facility or hospital should have a policy in place for the prevention, recognition, management and reporting of extravasation injuries (Gorski et al. 2016; RCN 2016). As a standard, the infusion should be stopped as soon as an extravasation injury is identified and the medical team informed. The device should not be removed, and an attempt to aspirate the extravasated drug should be made until the treatment plan has been determined (Al-Benna et al. 2013; RCN 2016).

\subsubsection{Hand Hygiene}

Hand hygiene is a key component of a group of evidence-based interventions to promote better outcomes for patients with a VAD (Gorski et al. 2016).

Hand hygiene prior to catheter maintenance combined with the correct aseptic technique dur- ing catheter manipulation provides protection against infection (WHO 2009; Loveday et al. 2014). Both patients and practitioners need to have a clear understanding of the importance of hand hygiene and the role that it plays in preventing the transmission of infection.

Hands should always be considered a source of infection. WHO (2009), Loveday et al. (2014), Gorski et al. (2016) and RCN (2016) recommend that hands are decontaminated with either soap and water or an alcohol sanitiser at these particular times:

1. When entering a patient's room or cubicle

2. Before patient contact

3. Before and after any procedure- - such as putting on gloves

4. After patient contact

5. After leaving the patient's environment

Poor hand hygiene can result in the spread of microorganisms between patients and poses a direct risk factor for VAD infections (Zhang et al. 2016). Improving hand hygiene requires a multimodal approach (WHO 2009), and programmes should include focus on behavioural changes such as empowering healthcare workers to be able to stop unsafe practices where physicians or other colleagues have breached hand hygiene protocols (Chopra and Saint 2015).

\subsubsection{Personal Protective Equipment (PPE)}

The selection of PPE is based on the assessment of the risk of transmission of microorganisms to the patient and the risk of contamination of practitioner's skin and clothing by the patient's blood or bodily fluids (Loveday et al. 2014).

Gloves should be worn for all invasive procedures, contact with sterile sites and non-intact skin, including when changing the dressing of a VAD (CDC 2011; Loveday et al. 2014).

Gloves should be single use and are put on immediately before an episode of patient care. Equally, gloves need to be removed as soon as the episode of care has been completed. Upon glove 
removal, hands are decontaminated with either soap and water or an alcohol-based sanitiser to prevent the spread of microorganisms from the hands (Moureau 2013; Loveday et al. 2014).

Additionally, the use of single-use disposable plastic aprons is recommended when there is a risk of blood or bodily fluid exposure (Loveday et al. 2014).

\subsubsection{Patient Skin Antisepsis}

The skin acts as a protective barrier against bacteria and infection. When the skin is punctured or breeched in any way, this barrier is broken, creating a portal for bacteria to enter the body. When bacteria enter the body through this portal of entry, they have the potential to migrate into the bloodstream and cause infection.

The skin is punctured during VAD insertion, creating a direct entry for bacteria to ingress into the bloodstream. Therefore, it is vitally important that the skin is disinfected at each dressing change and at any time that the skin puncture site is exposed.

Chlorhexidine is considered the antiseptic of choice when cleaning the skin before VAD dressing changes and is consistently recommended by current guidelines (Moureau 2013; Loveday et al. 2014; Gorski et al. 2016; RCN 2016). However, in a recent systematic review by Lai et al. (2016), the conclusion was that there is a low quality of evidence to suggest that antiseptic solutions containing chlorhexidine reduce catheter microbial colonisation and
CLABSI compared to antiseptic solutions containing povidone iodine.

Although antiseptics have traditionally been applied in a circular motion, current more up-todate products such as SoluPrep ${ }^{\mathrm{TM}}(3 \mathrm{M})$ and ChloraPrep $^{\mathrm{TM}}$ (CareFusion) now recommend applying antiseptic solutions in a back and forth grid-like pattern with friction to agitate the surface layers of the skin (Broadhurst et al. 2016).

It is crucially important that the antiseptic used is allowed to dry completely prior to the application of the dressing, as inadequate drying may cause contact dermatitis, inactivate the adhesion of the dressing or, in certain circumstances, increase the risk of infection due to moisture being trapped underneath the dressing. Current guidance on the antiseptics to be used and drying times is given below in Table 17.3.

Assessment of the skin underneath the dressing should be performed regularly as there is potential risk for skin injury due to age, underlying skin condition, joint movement and the presence of oedema. There is also a potential risk which needs to be assessed from medical adhesive-related skin injury (MARSI) associated with the use of adhesive-based engineered stabilisation devices (ESDs). The use of a skin barrier solution helps to reduce the risk of MARSI (Gorski et al. 2016).

\subsubsection{Aseptic Technique}

Asepsis is defined as the absence of pathogenic (harmful) organisms. Aseptic technique is a set of

Table 17.3 Current guidance regarding antiseptic drying times

\begin{tabular}{l|l|l|l}
\hline $\begin{array}{l}\text { Guidance for antiseptic } \\
\text { cleaning solutions }\end{array}$ & Epic3_Loveday et al. (2014) & $\begin{array}{l}\text { Infusion therapy standards } \\
\text { of practice-Gorski et al. } \\
(2016)\end{array}$ & $\begin{array}{l}\text { Standards for infusion therapy } \\
\text { (fourth edition)-RCN (2016) }\end{array}$ \\
\hline $\begin{array}{l}\text { Chlorhexidine in } \\
\text { alcohol }\end{array}$ & $\begin{array}{l}2 \% \text { chlorhexidine in } 70 \% \\
\text { alcohol }\end{array}$ & $\begin{array}{l}>0.5 \% \text { chlorhexidine in } \\
70 \% \text { alcohol }\end{array}$ & $\begin{array}{l}2 \% \text { chlorhexidine in 70\% } \\
\text { alcohol }\end{array}$ \\
\hline $\begin{array}{l}\text { Contraindications or } \\
\text { allergy to } \\
\text { chlorhexidine }\end{array}$ & Povidone iodine in alcohol & $\begin{array}{l}\text { Tincture } \\
\text { of iodine-idopher } \\
\text { Povidone iodine }\end{array}$ & Povidone iodine in alcohol \\
\hline $\begin{array}{l}\text { Drying times } \\
\text { Po exact timings given-but } \\
\text { emphasises that the antiseptic } \\
\text { solution should be dry }\end{array}$ & $\begin{array}{l}\text { Chlorhexidine in } \\
\text { alcohol-30 s } \\
\text { Povidone } \\
\text { iodine-90-120 s }\end{array}$ & $\begin{array}{l}\text { No exact timings given-but } \\
\text { emphasises that the antiseptic } \\
\text { solution should be dry }\end{array}$ \\
\hline
\end{tabular}


specific practices and procedures performed under carefully controlled conditions with the goal of minimising contamination by pathogens. During invasive procedures or maintenance of invasive devices, patients rely on staff to protect them from infection.

Aseptic technique should be followed when accessing any component of the intravenous device, site or line or when dressing changes are required (Loveday et al. 2014; Gorski et al. 2016; RCN 2016). However, despite clear guidance for the use of an aseptic technique when caring for the VAD, there is evidence of poor compliance (Moureau 2014). One of the biggest challenges in aseptic technique is convincing healthcare workers of the danger they pose to patients of microorganism transference during any invasive procedure.

To achieve safe aseptic practice, practitioners must have the ability to perform effective aseptic technique consistently. The concept of Aseptic Non Touch Technique (ANTT), which originated in the UK, provides a standardised approach to aseptic technique by providing clear, uncomplicated steps to encourage compliance (Rowley and Clare 2009; Loveday et al. 2014). The essential components of an aseptic technique include hand hygiene, use of personal protective equipment and the promotion of a practice technique to minimise contamination from bacteria (Rowley and Clare 2009; O'Grady et al. 2011; Loveday et al. 2014).

\subsection{Device Necessity}

Check the catheter daily to ensure that the VAD is still required based on the patient's medical condition and treatment plan (Pronovost et al. 2006; CDC 2011; Moureau 2013; Gorski et al. 2016).

The practitioner should:

- Check the patient's prescribed therapy to see if the catheter is still necessary.

- Check to see if the intravenous treatment is complete or if the treatment can be switched to an oral form of the medication.
- Check if the VAD is being used for blood sampling only.

Since VADs are a proven source of infection, they should be removed as soon as they are no longer medically necessary to reduce the risk of infection (Pronovost et al. 2006; Gorski et al. 2016). This includes checking to see if the treatment can be switched to an oral form of the medication rather than intravenous treatment. As an infection prevention measure, change to an oral medication if possible. The best way to eliminate catheter infections is to eliminate the catheter as soon as possible.

Gorski et al. (2016) and RCN (2016) standards state that the VAD should be removed if there is an unresolved complication, if therapy has been discontinued or if it is no longer deemed medically necessary. Additionally, a catheter that is no longer necessary should not be kept in place just in case it may be needed in a few days, and consideration should be made to switch to oral medication as soon as a patient's condition allows to aid in the prompt removal of the VAD at the earliest possible time. This timely removal of the VAD when it is no longer necessary will assist in the minimisation of the infection risk.

\subsection{Care Bundles/Compliance and Education}

There is a plethora of evidence from Pronovost et al. (2006) onwards to demonstrate that the implementation of care bundles and ongoing maintenance for VAD care has a significant effect on reducing the risks of complications including infections (Pronovost et al. 2006; New et al. 2014; Duffy et al. 2015; Matthias Walz et al. 2015).

Components of the care bundle/maintenance programme should include procedural guidelines for hygiene, aseptic technique, dressing changes and a daily or more frequent assessment of the device for function, complications and signs and symptoms of infection. Failure to complete one of these components predisposes the patient to a 
bloodstream infection or other complications (Duffy et al. 2015).

It is essential that everyone involved in the care of the patient with a VAD is trained through structured and well-organised educational programmes that enable practitioners to provide, monitor and evaluate care and continually increase their competence which are crucial to the success of any strategy designed to reduce the risk of infection (Bianco et al. 2013; Loveday et al. 2014). Written policies, formal training and years of experience all contribute to an increase in knowledge, practice, positive attitudes towards CLABSI prevention and improved patient outcomes.

\subsection{Summary}

Practitioners need to be confident and proficient in VAD care practices and be aware of the signs and symptoms of clinical infection or complications affecting a VAD. It is essential that everyone involved in the care of the patient with a VAD has adequate training to identify complications, understand interventions and be aware of the need for documentation in the medical record. An in-depth assessment of each VAD performed daily or with each shift should evaluate the insertion site, the adherence of the dressing, the function of the device and the response of the patient to any associated pain. Structured and wellorganised educational programmes that enable practitioners to provide, monitor and evaluate care and continually increase competence are crucial to the success of any strategy designed to reduce the risk of infection and other complications (Bianco et al. 2013; Loveday et al. 2014). Written policies, formal training and years of experience all contribute to an increase in knowledge, practice, positive attitudes towards CLABSI prevention and improved patient outcomes. The most important single action that can be performed by clinicians to reduce risk is the removal of unnecessary VAD, those that are not being used, where treatment is complete and when oral medications have been instituted.

\section{Case Study}

Kelly is a newly qualified nurse responsible for performing an assessment on Mr. Smith a 72-year-old stroke patient with a urinary tract infection. Mr. Smith is receiving IV antibiotics through a peripheral catheter in his left hand. Kelly performs a site assessment of the PIVC and notes it is placed in the hand with limited mobility. No drainage or redness is present, but Kelly identifies swelling surrounding the insertion site, in the hand and up the arm.

Kelly speaks with her preceptor who states if a complication is present, the PIVC needs to be discontinued and another restarted in a different location. Kelly discontinues the PIVC by loosening the dressing gently, applying pressure with a sterile gauze, and removes the catheter. A dry sterile dressing is applied. Kelly then seeks the assistance of a more experienced nurse to assist her with locating a suitable site for insertion of a new PIVC.

\section{Summary of Key Points}

1. The care and maintenance of a vascular access device (VAD) is equally as important as the insertion procedure in preventing complications and infection.

2. Assessments of the VAD should be carried out daily or more frequently depending on the type of VAD and the category of patient.

3. An assessment should include:
(a) The cannula site
(b) The integrity of the patient's skin, the type of dressing and how frequently the dressing needs to be changed
(c) Catheter function
(d) Tubing/giving set
(e) Assessment for signs of complica- tions or infection
(f) Necessity for the device
(g) Documentation 
4. Hand hygiene must be performed prior to any VAD assessment or procedure.

5. An aseptic technique should be used for any VAD procedure.

6. A VAD should be removed as soon as it is deemed no longer medically necessary.

\section{References}

Al-Benna S, O’Boyle C, Holley J. Extravasation injuries in adults. ISRN Dermatol. 2013;2013:856541.

Bianco A, Coscarelli P, Nobile CGA, Pileggi C, Pavia $\mathrm{M}$. The reduction of risk in central line-associated bloodstream infections: knowledge, attitudes and evidence-based practices in health care workers. Am J Infect Control. 2013;41:107-12.

Bodenham A, Babu S, Bennett J, Binks R, Fee P, Fox B, Johnston AJ, Klein AA, Langton JA, McLure H, Tighe SQM. Association of anaesthetists of great Britain and Ireland: safe vascular access 2016. Anaesthesia. 2016;71:573-585. www.aagbi.org/sites/default/files/ safe20\%vascular\%access\%202016.pdf. Accessed 2 April 2017.

Broadhurst D, Moureau N, Ullman AJ. Central venous access devices site care practices: an international survey of 34 countries. J Vasc Access. 2016;17(1):78-86.

Center for Disease Control and Prevention. 2011 guidelines for the prevention of intravascular catheterrelated infection. Atlanta: CDC; 2011. p. 1-83. www. cdc.gov/hicpac.BSI/BSI-guidelines-2011.html. Accessed 17 March 2017.

Chapman AL, Seaton RA, Cooper MA, Hedderwick S, Goodall V, Reed C, Sanderson F, Nathwani D. Good practice recommendations for outpatient parenteral antimicrobial therapy (OPAT) in adults in the UK: a consensus statement. J Antimicrob Chemother. 2012;67:1053-62.

Chopra V, Saint S. Vascular catheter infections: time to get technical. Lancet. 2015;386:2034-6.

Davis J. Central line associated bloodstream infection: comprehensive, data-driven prevention. PA Patient Saf Advis. 2011;8(3):100-5.

Duffy EA, Rodgers CC, Shever LL, Hockenberry MJ. Implementing a daily maintenance care bundle to prevent central line-associated bloodstream infections in pediatric oncolgy patients. J Pediatr Oncol Nurs. 2015;32(6):394-400.

Dwyer V, Rutkowski B. IV infiltration and extravasation: prevention, recognition, and intervention. J Assoc Vasc Access. 2016;21(4):253.

Gorski L, Hadaway L, Hagle M, McGoldrick M, Orr M, Doellman D. Infusion therapy: standards of practice (supplement 1). J Infus Nurs. 2016;39(1S):S1-S159.
Hallam C, Weston V, Denton A, Hill S, Bodenham A, Dunn H, Jackson T. Development of the UK vessel health and preservation (VHP) framework: a multi-organisational collaborative. J Infect Prev. 2016;17(2):65-72.

Jackson A. Infection control: a battle in vein infusion phlebitis. Nurs Times. 1998;94(4):68-71.

Lai NM, Lai NA, O'Riordan E, Chaiyakunapruk N, Taylor JE, Tan K. Skin antisepsis for reducing central venous catheter-related infections. Cochrane Database Syst Rev. 2016;7:CD010140. https://doi. org/10.1002/14651858.CD010140.pub2.

Loveday HP, Wilson JA, Pratt RJ, Golsorkhi M, Tingle A, Bak A, Browne J, Prieto J, Wilcox M. Epic3: National evidence-based guidelines for preventing healthcareassociated infections in NHS hospitals. J Hosp Infect. 2014;86(Suppl 1):S1-S70.

Marsh N, Mihala G, Ray-Barruel G, Webster J, Wallis MC, Rickard CM. Inter-rater agreement on PIVCassociated phlebitis signs, symptoms and scales. J Eval Clin Pract. 2015;21:893-9.

Matthias Walz J, Ellison RT, Mack DA, Flaherty HM, McIIwaine JK, Whyte KG, Landry KE, Baker SP, Heard SO, CCoc Research Group. The bundle 'plus': the effect of a multi-disciplinary team approach to eradicate central line-associated bloodstream infections. Anesth Analg. 2015;120(4):868-76.

Moureau N. Safe patient care when using vascular access devices. Br J Nurs. 2013;22(2):S14-21.

Moureau NL. Catheter associated bloodstream infection prevention: what is missing? $\mathrm{Br} \mathrm{J}$ Healthc Manag. 2014;20(11):502-10.

Moureau NL, Trick N, Nifong T, Perry C, Kelley C, Leavett M, Gordon SM, Wallace J, Harvill M, Biggar C, Doll M, Papke L, Benton L, Phelan DA. Vessel health and preservation (part 1): a new evidencebased approach to vascular access selection and management. J Vasc Access. 2012;13:351-6.

National Institute for Health. Infection prevention and control. Quality standard [QS61]. Quality standard 5: vascualr access devices. [online] available: www. nice.org.uk/guidance/qs61/chapter/Quality-statement5-vascular-access-devices [accessed: January 2018] (Regulatory); 2014.

New KA, Webster J, Marsh NM, Hewer B. Intravascular device use, management, documentation and complications; a point prevalence survey. Aust Health Rev. 2014;38:345-9.

O'Grady NP, Alexander M, Burns LA, Dellinger EP, Garland J, Heard SO, Lipsett PA, Masur H, Mermel LA, Pearson ML, Raad II, Randolph AG, Rupp ME, Saint S, the Healthcare Infection Control Practices Advisory Committee (HICPAC). Guidelines for the prevention of intravascular catheter-related infections. Clin Infect Dis. 2011;52:e162-93.

Pronovost P, Needham D, Berenholtz S, et al. An intervention to decrease catheter-related bloodstream infections in the ICU. N Engl J Med. 2006;355(26):2725-32.

Ray-Barruel G, Polit D, Murfield J, Rickard C. Infusion phlebitis assessment measures: a systmatic review. J Eval Clin Pract. 2014;20(2):191-202. 
Rowley S, Clare S. Improving standards of aseptic practice through ANTT trust-wide implementation process: a matter of prioritisation and care. J Infect Prev. 2009;10(1 Supplement):S18-23.

Royal College of Nursing. Standards for infusion therapy. 4th ed. London: RCN; 2016.

Rupp ME, Cassling K, Faber H, Lyden E, Tyner K, Marion N, Van Schooneveld T. Hospital-wide assessment of compliance with central venous catheter dressing recommendations. Am J Infect Control. 2013;41:89-91.

Tice AD, Rehm SJ, Dalovisio JR, Bradley JS, Martinelli LP, Graham DR, Brooks Gainer R, Kunkkel MJ, Yancey RW, Williams DN. Practice guidelines for outpatient parenteral antimocrobial therapy. Clin Infect Dis. 2004;38(12):1651-71.

Timsit JF, Mimoz O, Mourvillier B, Souweine B, Garrouste-Orgeas M, Alfandari S, Plantefeve G, Bronchard R, Trche G, Gauzit R, Antona M, Canet E, Bohe J, Lepape A, Vesin A, Arrault X, Schwebel
C, Adrie C, Zahar JR, Ruckly S, Touregros C, Lucet JC. Randomised controlled trial of chlorhexidine dressing and highly adhesive dressing for preventing catheter-related infections in critically ill adults. Am J Respir Crit Care Med. 2012;186(12):1272-8.

Ullman AJ, Cooke ML, Mitchell M, Lin F, New K, Long DA, Mihala G, Rickard CM. Dressings and securement devices for central venous catheters (CVC) (review). Cochrane Database Syst Rev. 2015;(9):CD010367. https://doi.org/10.1002/14651858.CD010367.pub2.

World Health Organisation. A guide to the implementation of the WHO multimodal hand hygiene improvement strategy. 2009. http://apps.who.int/iris/ bitstream/10665/70030/1/WHO_IER_PSP_2009.02_ eng.pdf.

Zhang L, Cao S, Marsh N, Ray-Barruel G, Flynn J, Larsen E, Richard CM. Infection risks associated with peripheral vascular catheters. J Infect Prev. 2016;17(5):207-13.

Open Access This chapter is licensed under the terms of the Creative Commons Attribution 4.0 International License (http://creativecommons.org/licenses/by/4.0/), which permits use, sharing, adaptation, distribution and reproduction in any medium or format, as long as you give appropriate credit to the original author(s) and the source, provide a link to the Creative Commons license and indicate if changes were made.

The images or other third party material in this chapter are included in the chapter's Creative Commons license, unless indicated otherwise in a credit line to the material. If material is not included in the chapter's Creative Commons license and your intended use is not permitted by statutory regulation or exceeds the permitted use, you will need to obtain permission directly from the copyright holder. 